\title{
Construction of a eukaryotic expression system for granulysin and its protective effect in mice infected with Mycobacterium tuberculosis
}

Correspondence

Binbo Liu

|bbbbl@163.com

Received 3 May 2006

Accepted 27 June 2006
Binbo Liu, ${ }^{1}$ Shengwu Liu, ${ }^{2}$ Xueju $\mathrm{Qu}^{2}$ and Junyan Liu ${ }^{2}$

Department of Microbiology ${ }^{1}$ and Department of Immunology ${ }^{2}$, School of Medicine, Wuhan University, Wuhan 430071, People's Republic of China

\section{INTRODUCTION}

Tuberculosis (TB), caused by the bacterium Mycobacterium tuberculosis, is a major infectious disease problem, with onethird of the world's population infected, 8 million people developing the active disease, and about 3 million people dying of TB each year around the world (Marting, 2001). A steady increase in drug-resistant strains of $M$. tuberculosis with a high prevalence of HIV infection has led to the reduced efficacy of the traditional anti-TB drugs (Ken \& Clifton, 2004). Thus the development of better drugs is urgently needed to prevent the transmission of $M$. tuberculosis.

Granulysin is an effector molecule co-localized with perforin and granzymes in cytolytic granules of human natural killer (NK) cells and cytotoxic T lymphocytes (CTLs), and is released through granule exocytosis (Pena \& Krensky, 1997). In vitro, recombinant granulysin has a wide range of antimicrobial effects on bacteria, fungi and parasites (Stenger et al., 1998, 1999; Ma et al., 2002). It is able to induce a cytolytic effect against tumour cell lines (Gamen et al., 1998; Kaspar et al., 2001; Julian et al., 2001). Furthermore, recombinant granulysin is able to kill extracellular M. tuberculosis, and intracellular M. tuberculosis of infected macrophages, in the presence of perforin (Stenger et al., 1998).

In our current work, we constructed a eukaryotic expression plasmid for granulysin, and evaluated its protective effect in mice infected with M. tuberculosis.

Abbreviations: CTL, cytotoxic T lymphocyte; H\&E, haematoxylin and eosin; NK cell, natural killer cell; PBMC, peripheral blood mononuclear cell; TB, tuberculosis; WI, weight index.

\section{METHODS}

Preparation of peripheral blood mononuclear cells (PBMCs). PBMCs from a healthy volunteer were isolated from heparinized blood by Ficoll-Hypaque gradient centrifugation and were cultured to $10^{6}$ c.f.u. $\mathrm{ml}^{-1}$ in complete RPMI 1640 medium (Gibco) supplemented with $10 \%(\mathrm{v} / \mathrm{v})$ heat-inactivated fetal calf serum (Gibco), $2 \mathrm{mM}$ L-glutamine, $20 \mathrm{mM}$ HEPES and $100 \mathrm{U} \mathrm{ml}^{-1}$ double antibiotic (penicillin/streptomycin). PBMCs were cultured for 5 days at $37^{\circ} \mathrm{C}$ in the presence of $5 \%(\mathrm{v} / \mathrm{v}) \mathrm{CO}_{2}, 75 \mathrm{mg}$ phytohaemagglutinin (PHA) $\mathrm{ml}^{-1}$, and $20 \mathrm{U}$ rIL-2 $\mathrm{ml}^{-1}$.

Construction and identification of expression plasmid. PBMCs were harvested and washed twice with PBS, total RNA was extracted from the PBMCs, and RT-PCR was performed to amplify the cDNA of granulysin. PCR products were purified after electrophoresis in a $1 \cdot 2 \%(\mathrm{v} / \mathrm{v})$ agarose gel and were analysed by sequencing. The primers were as follows: sense, $5^{\prime}$-AT CTC GAG ATG GGC CGT GAC TAC AGG ACC-3' (with a XhoI restriction site and start code); antisense, 5'-GA GAA TTC TCA CCT GAG GTC CTC ACA GAT-3' (with an EcoRI site and stop code). The purified products were digested with restriction enzymes XhoI and EcoRI, and ligated with the pcDNA3.1(-) vector. The recombinant plasmids were transferred into Escherichia coli $\mathrm{DH} 5 \alpha$, and identified using restriction enzymes and sequencing. The recombinant plasmids were purified and prepared by adjusting the plasmids to a final concentration of $1 \mathrm{mg} \mathrm{DNA} \mathrm{ml}^{-1}$ in physiological saline.

SDS-PAGE and Western blot. COS7 cells were transfected with the recombinant granulysin plasmids or with empty vector, as described in the instructions for the Lipofectamine 2000 reagent (Invitrogen). Cells were seeded into selection medium containing G418 until G418-resistant clones were obtained, and were then harvested and lysed for Western blot analysis. The solubilized proteins were subjected to SDS-PAGE on $15 \%(\mathrm{v} / \mathrm{v})$ polyacrylamide gel and transferred onto a nitrocellulose membrane. The membrane was blocked for $1 \mathrm{~h}$ at room temperature in blocking buffer $(3 \%$, w/v, BSA in PBS, $0.05 \%$ Tween 20). Next, the membrane was first incubated with anti-granulysin $\mathrm{mAb}$ at $1: 300$ dilution in blocking 
buffer, and then with peroxidase-conjugated rabbit anti-goat IgG at 1:500 dilution. After washing, the bound antibodies were visualized with diaminobenzidine (DAB).

Animal model of infection with $M$. tuberculosis. Eighteen $\mathrm{BALB} / \mathrm{c}$ male mice (SPF grade, body weight 18-20 g, 6 weeks old, obtained from the Animal Center of Wuhan University) were divided into three groups randomly: the physiological saline group, the pcDNA3.1(-) group and the granulysin plasmid group. Mice were challenged with $M$. tuberculosis $\left(8 \times 10^{6}\right.$ c.f.u.) at the lateral tail to prepare the animal model. On day 3 before challenging with bacteria, mice were injected intramuscularly in the quadriceps muscle of each hind leg with a total of $100 \mu \mathrm{l}$ granulysin rDNA. On day 3 after challenging with bacteria, mice were immunized again. Control mice were immunized with physiological saline or parental vector pcDNA3.1(-).

Spleen weight index (WI). After 4 weeks of infection, mice were killed, the body weight of each mouse and its spleen weight were taken, and the WI was counted as follows: $\mathrm{WI}=$ spleen weight $\times 100 /$ body weight.

c.f.u. determination. Four weeks after injection with M. tuberculosis, mice were sacrificed for assessment of bacterial growth. After lungs and spleens were removed aseptically, $0.5 \mathrm{~g}$ of each organ was homogenized aseptically in $0.5 \mathrm{ml}$ physiological saline. The homogenates were coincubated with $0.5 \mathrm{ml} 4 \%(\mathrm{v} / \mathrm{v}) \mathrm{H}_{2} \mathrm{SO}_{4}$ for $20 \mathrm{~min}$, then were diluted serially in physiological saline, and $0 \cdot 1 \mathrm{ml}$ aliquots of each sample were plated on 7H11 agar (Difco). The numbers of c.f.u. in infected organs were determined after 4 weeks' incubation at $37^{\circ} \mathrm{C}$.

Histopathological analysis. Lung and spleen tissues were fixed with $4 \%(\mathrm{v} / \mathrm{v})$ paraformaldehyde and embedded in paraffin for sectioning. The tissues were subjected to haematoxylin and eosin (H\&E) or acid-fast bacillus staining, and evaluated by light microscopy.

Mycobactericidal activity in vitro. Eighteen $\mathrm{BALB} / \mathrm{c}$ male mice were randomized into three groups, and injected intramuscularly with plasmid DNA. The mice and the immunization methods were the same as above. One week after the last immunization, the serum of each mouse was harvested. Serum was serially diluted and coincubated with $M$. tuberculosis $\left(1 \times 10^{4}\right.$ c.f.u. $)$ for $72 \mathrm{~h}$. Then, a part of the serum was plated on 7H11 agar for assessment of c.f.u., and the remainder was fixed for scanning electron microscopy detection.

Statistical analysis. The statistical significance of experimental data was determined by Student's $t$ test. Differences with $P<0 \cdot 05$ were considered significant.

\section{RESULTS}

\section{Construction and identification of the recombinant plasmid}

A 242 bp fragment was isolated by RT-PCR from PBMCs. Sequence analysis of PCR products was performed, and the sequence of PCR products was the same as that reported elsewhere (Manning et al., 1992). The amplification products were purified and digested with XhoI and EcoRI to construct a recombinant plasmid by insertion into the pcDNA3.1(-) vector. The recombinant vector was treated with the two restriction enzymes XhoI and EcoRI, and a 242 bp fragment was obtained (Fig. 1), and the result of rDNA sequence analysis confirmed the correct sequence and reading frame.

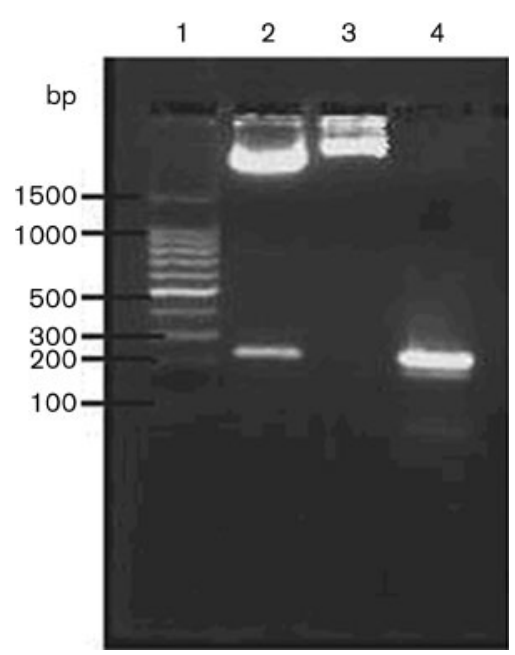

Fig. 1. Identification of recombinant plasmid. Lanes: 1, DNA marker; 2, Xhol- and EcoRI-digested recombinant granulysin plasmid; 3, pcDNA3.1(-); 4, PCR products.

\section{Western blot analysis of protein expression}

COS7 cells were transfected with granulysin rDNA or empty vector. The cells were harvested and lysed, and subjected to SDS-PAGE and Western blot analysis. The results of SDSPAGE showed that among the transfected COS7 cellular lytic proteins, a strong specific band was found at $\sim 9 \mathrm{kDa}$ (Fig. 2). Western blotting confirmed that the $9 \mathrm{kDa}$ protein was bound by anti-granulysin $\mathrm{mAb}$, demonstrating that the granulysin cDNA was expressed in COS7 cells (Fig. 3).

\section{Spleen WI}

The WI of spleen of granulysin group mice $(2 \cdot 575 \pm 0 \cdot 649)$ was significantly lower than that of physiological saline group mice $(4 \cdot 580 \pm 0 \cdot 967, P<0 \cdot 01)$ and pcDNA3.1 $(-)$

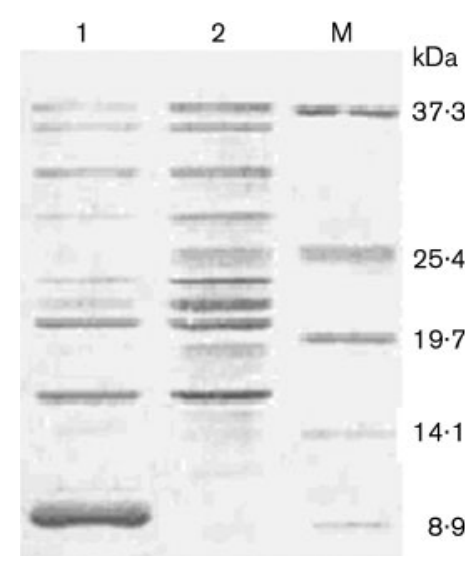

Fig. 2. SDS-PAGE analysis of granulysin expression in COS7 cells. Lanes: 1, COS7 cells transfected with granulysin rDNA; 2 , COS7 cells transfected with pcDNA3.1(-); M, protein markers. 


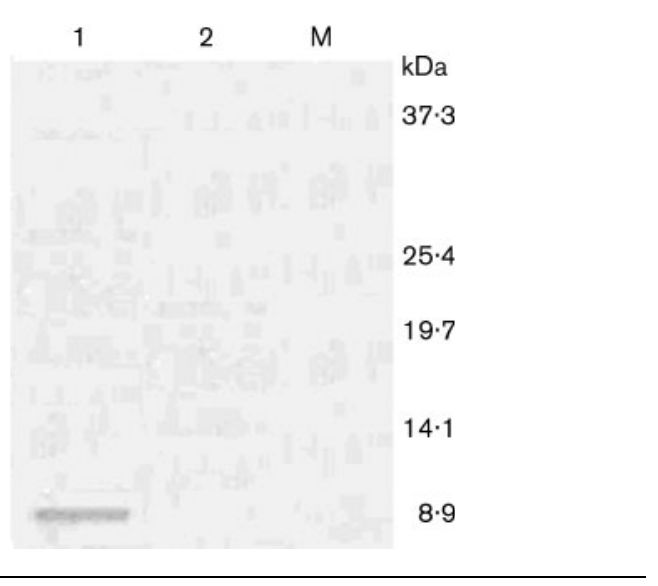

Fig. 3. Western blot analysis of granulysin expression in COS7 cells. Lanes: 1, 9 kDa granulysin protein; 2, COS7 cells transfected with pcDNA3.1(-); M, protein markers.

group mice $(3 \cdot 885 \pm 0 \cdot 228, P<0 \cdot 01)$. There was no significant difference between the two control groups.

\section{c.f.u. in lung and spleen}

The numbers of viable bacteria $\left[\log _{10}\right.$ (c.f.u.) $\left.\mathrm{g}^{-1} \mathrm{ml}^{-1}\right]$ in lung of granulysin-plasmid-immunized mice $(6 \cdot 688 \pm 0 \cdot 003)$ were significantly lower than those of physiological saline group mice $(7 \cdot 821 \pm 0 \cdot 090, P<0 \cdot 01)$ and pcDNA3.1(-) group mice $(7 \cdot 848 \pm 0 \cdot 017, P<0 \cdot 01)$. In addition, the numbers of viable bacteria $\left[\log _{10}\right.$ (c.f.u.) $\left.\mathrm{g}^{-1} \mathrm{ml}^{-1}\right]$ in spleen of granulysin-plasmid-immunized mice $(7 \cdot 140 \pm 0 \cdot 034)$ were significantly lower than those of physiological saline group mice $(7 \cdot 805 \pm 0 \cdot 080, P<0 \cdot 01)$ and $\mathrm{pcDNA3} .1(-)$ group mice $(7 \cdot 858 \pm 0 \cdot 043, P<0 \cdot 01)$. There was no significant difference between the two control groups.

\section{Pathological changes in lung}

Lungs from mice of different groups were fixed, sectioned and stained with $\mathrm{H} \& \mathrm{E}$ staining for assessment of tissue damage. In granulysin group mice, a part of the alveolar tissue appeared to be intact, with slight lung inflammation, and the other part of the alveolar tissue showed granulomatous lesions with large numbers of lymphocytes and macrophages; no appreciable necrosis appeared (Fig. 4b). However, in two control group mice, almost all of the lung tissue was consolidated, and no intact alveolar tissue was observed; seroplastic infiltration, necrosis and granulomas were observed with large numbers of lymphocytes and macrophages (Fig. 4a). No significant pathological changes in the spleen were observed among mice of the three groups.

Acid-fast bacillus staining of lung and spleen tissue showed that the bacterial loading of granulysin group mice (Fig. 4d) was much less than that of mice of the two control groups (Fig. 4c).
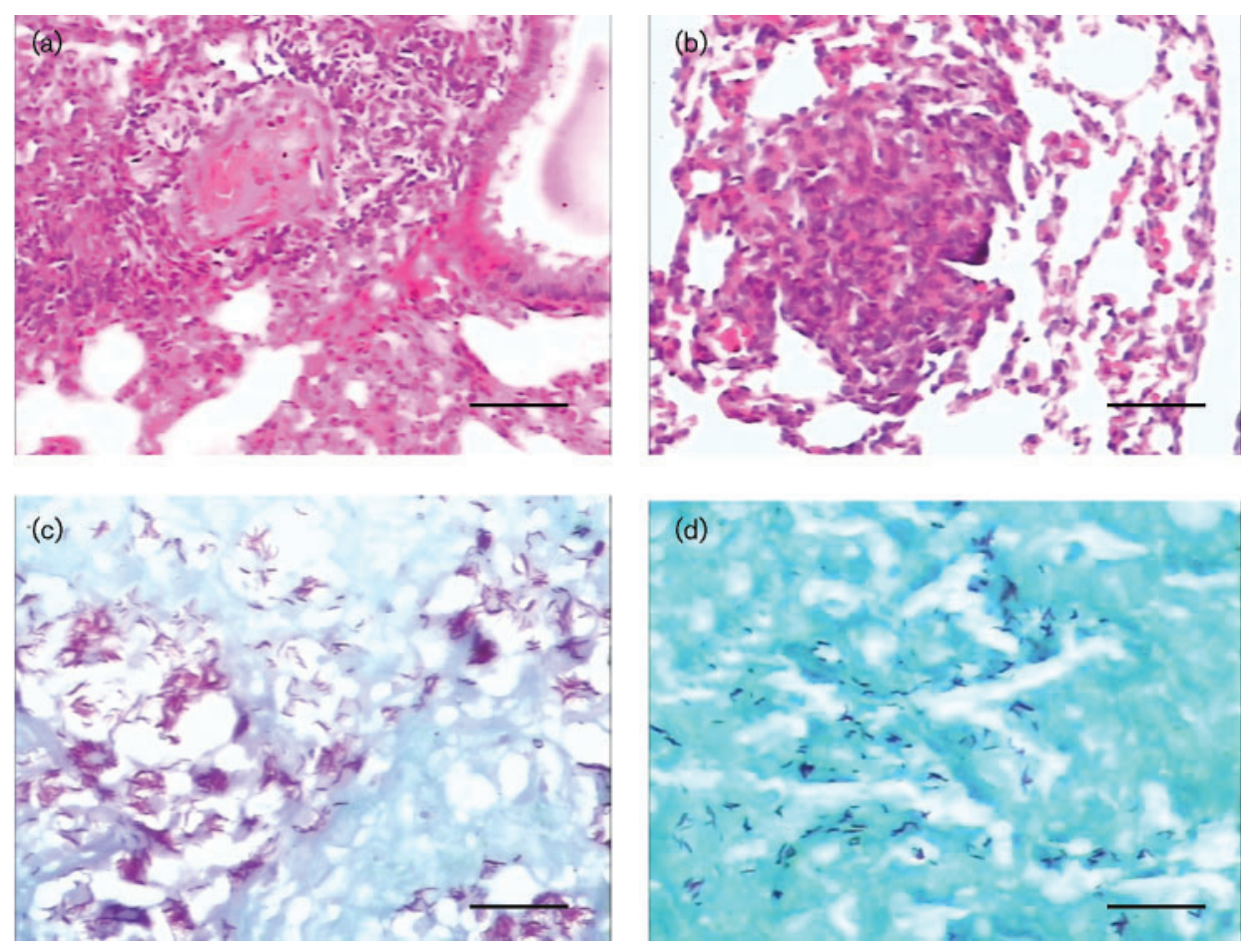

Fig. 4. Results of histopathological analysis. (a) H\&E staining $(\times 200)$ of lung tissue from pcDNA3.1(-) group mice; (b) H\&E staining $(\times 200)$ of lung tissue from granulysin group mice; (c) acid-fast bacillus staining $(\times 400)$ from pcDNA3.1( -$)$ group mice; (d) acid-fast bacillus staining $(\times 400)$ from granulysin group mice. Bars, $(a, b) 0.02 \mu \mathrm{m} ;(c, d), 0.04 \mu \mathrm{m}$. 
Table 1. Viable bacteria numbers in diluted serum of mice Values shown are $\log _{10}$ (c.f.u.) $\mathrm{g}^{-1} \mathrm{ml}^{-1}$ (mean $\pm \mathrm{SD}$ ).

\begin{tabular}{|lcccc|}
\hline Group & \multirow{n}{*}{ Dilution } \\
\cline { 2 - 5 } & & $\mathbf{1 : 2}$ & $\mathbf{1 : 4}$ & $\mathbf{1 : \mathbf { 8 }}$ \\
\hline Saline & 6 & $2 \cdot 971 \pm 0 \cdot 010$ & $2 \cdot 991 \pm 0 \cdot 013$ & $3 \cdot 006 \pm 0 \cdot 061$ \\
PcDNA3.1(-) & 6 & $3 \cdot 030 \pm 0 \cdot 035$ & $3 \cdot 020 \pm 0 \cdot 049$ & $3 \cdot 013 \pm 0 \cdot 052$ \\
Granulysin & 6 & $2 \cdot 362 \pm 0 \cdot 088^{*}$ & $2 \cdot 735 \pm 0 \cdot 051^{*}$ & $2 \cdot 936 \pm 0 \cdot 149$ \\
\end{tabular}

${ }^{\star} P<0.01$ versus saline group and pcDNA3.1(-) group.

\section{Mycobactericidal activity in vitro}

Serum of each mouse immunized with plasmids was harvested, serially diluted and coincubated with $M$. tuberculosis for c.f.u. determination. As shown in Table 1, diluted serum of recombinant-plasmid-immunized mice reduced the numbers of viable bacteria significantly with respect to mice of the two control groups, and showed a dose-dependent growth inhibition against M. tuberculosis. The percentage killing of $M$. tuberculosis by the diluted serum was as follows: at $1: 2,78 \cdot 54 \%$; at $1: 4,48 \cdot 23 \%$; and at $1: 8,16 \cdot 21 \%$.

The results of scanning electron microscopy showed that the serum of recombinant-plasmid-immunized mice resulted in the formation of marked lesions in the bacterial surface (Fig. 5).

\section{DISCUSSION}

Peptide antibiotics are produced by many species, ranging from plants and insects to lower vertebrates and mammals (Lehrer \& Ganz, 1999; Kim et al., 2003). They can kill bacteria, as well as fungi, parasites and tumour cells, by the
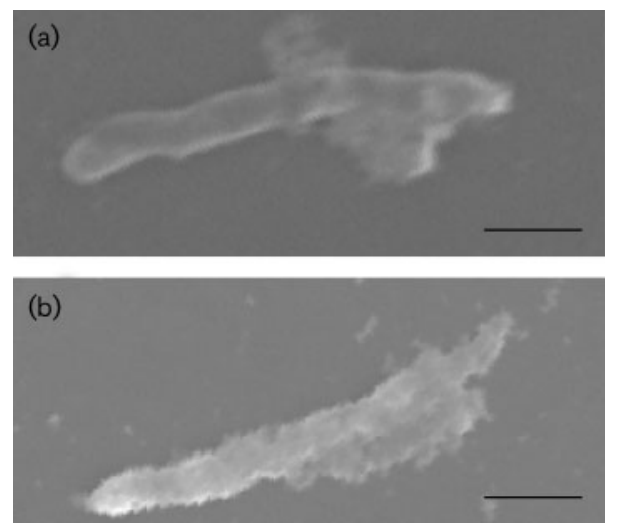

Fig. 5. Granulysin-induced lesions in the mycobacterial cell surface. (a) M. tuberculosis in diluent of pcDNA3.1(-) group mice $(\times 10000)$; (b) M. tuberculosis in diluent of granulysin group mice $(\times 10000)$. Bar, $1 \mu \mathrm{m}$. physical disruption of cell membranes, and this makes them promising antibacterial agents (Honcock, 1997).

Granulysin is one of the peptide antibiotics produced by human CTLs and NK cells, and is a cytolytic molecule present in human CTL and NK cell granules. It was first identified by subtractive hybridization of CTL minus B-cell mRNA, and is specifically expressed by CTLs and NK cells 3-5 days after activation (Jongstra et al., 1987; Pena et al., 1997). Granulysin can reduce the viability of a broad spectrum of pathogenic bacteria, fungi and parasites in vitro. It can directly kill extracellular M. tuberculosis, and, in combination with perforin, decrease the viability of intracellular M. tuberculosis.

In the current work, we constructed a eukaryotic granulysin expression plasmid, and injected the recombinant plasmid into the muscles of mice infected with $M$. tuberculosis to evaluate its protective effect. We found that granulysin significantly decreased the WI of spleen, and reduced the numbers of viable bacteria in lung and spleen of granulysinrDNA-immunized mice compared with those of control group mice. We also found that granulysin resulted in significantly reduced lung pathology with much less alveolitis and necrosis, and fewer granulomatous lesions compared with that of physiological-saline- or empty-DNAvector-immunized mice. In vitro, the serum of the recombinant-plasmid-immunized mice inhibited the viability of $M$. tuberculosis by the physical disruption of cell membranes. To the best of our knowledge, our work is the first to prove the protective effect of a eukaryotic granulysin expression plasmid in mice infected with M. tuberculosis, and may provide new insights in TB control.

\section{ACKNOWLEDGEMENTS}

This work was supported by the Key Scientific and Technological Project of Wuhan no. 301121028.

\section{REFERENCES}

Gamen, S., Hanson, D. A., Kaspar, A., Naval, J., Krensky, A. M. \& Anel, A. (1998). Granulysin-induced apoptosis.I. Involvement of at least two distinct pathways. J Immunol 161, 1758-1764.

Honcock, R. E. W. (1997). Peptide antibiotics. Lancet 349, 418-22.

Jongstra, J., Schall, T. J., Dyer, B. J., Clayberger, C., Jorgensen, J., Davis, M. M. \& Krensky, A. M. (1987). The isolation and sequence of a novel gene from a human functional $\mathrm{T}$ cell line. J Exp Med 165, 601-614.

Julian, P., Patricia, P. G., Gamen, S. \& 8 other authors (2001). A role of the mitochondrial apoptosis-inducing factor in granulysininduced apoptosis. J Immunol 167, 1222-1229.

Kaspar, A. A., Okada, S. \& Kumar, J. (2001). A distinct pathway of cell-mediated apoptosis initiated by granulysin. J Immunol 167, 350-356.

Ken, D. \& Clifton, E. B. (2004). Prospects for new antitubercular drugs. Curr Opin Microbiol 7, 460-465. 
Kim, S., Kim, S. S., Bang, Y. J., Kim, S. J. \& Lee, B. J. (2003). In vitro activities of native and designed peptide antibiotics against drug sensitive and resistant tumor cell lines. Peptides 24, 945-953.

Lehrer, R. \& Ganz, T. (1999). Antimicrobial peptides in mammalian and insect host defence. Curr Opin Immunol 11, 23-27.

Ma, L. L., Spurrell, J. C. L., Wang, J. F., Neely, G. G., Epelman, S., Krensky, A. M. \& Mody, C. H. (2002). CD8 T cell-mediated killing of Cryptococcus neoformans requires granulysin and is dependent on CD4 T cells and IL-15. J Immunol 169, 5787-5795.

Manning, W. C., O'Farrell, S., Goralski, T. J. \& Krensky, A. M. (1992). Genomic structure and alternative spilicing of 519, a gene expressed later after T cell activation. J Immunol 148, 4036-4042.

Marting, E. (2001). Driving a stake into resurgent TB. Science 293, 234-235.
Pena, S. V. \& Krensky, A. M. (1997). Granulysin, a new human cytolytic granule-associated protein with possible involvement in cell-mediated cytotoxicity. Semin Immunol 9, 117-125.

Pena, S. V., Hason, D. A., Carr, B. A., Goralski, T. J. \& Krensky, A. M. (1997). Processing subcellular localization, and function of 519 (granulysin), a human late $\mathrm{T}$ cell activation molecule with homology to small, lytic, granule proteins. J Immunol 158, 2680-2688.

Stenger, S., Hanson, D. A., Teitelbaum, R. \& 11 other authors (1998). An antimicrobial activity of cytolytic $\mathrm{T}$ cells mediated by granulysin. Science 282, 121-125.

Stenger, S., Rosat, J.-P., Bloom, B. R., Krensky, A. M. \& Modlin, R. L. (1999). Granulysin: a lethal weapon of cytolytic T cells. Immunol Today 20, 390-394. 